\title{
Giuditta Parolini \\ In pursuit of a science of agriculture: the role of statistics in field experiments
}

\section{Article, Postprint version}

This version is available at http://dx.doi.org/10.14279/depositonce-6754.

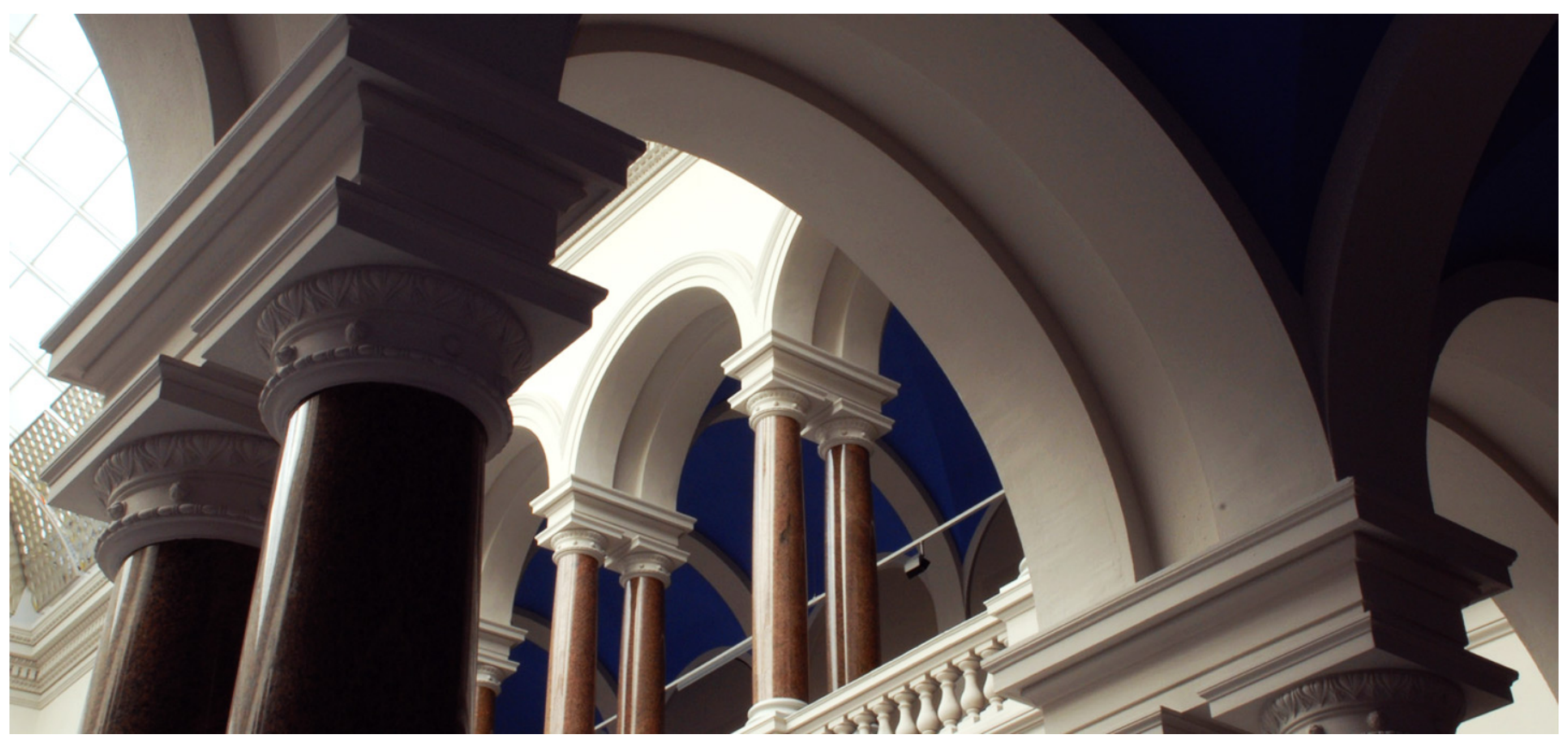

\section{Suggested Citation}

Parolini, Giuditta: In pursuit of a science of agriculture: the role of statistics in field experiments. - In:

History and philosophy of the life sciences. - ISSN: 1742-6316 (online), 0391-9714 (print). - 37 (2015), 3.

- pp. 261-281. - DOI: 10.1007/s40656-015-0075-9. (Postprint is cited, page numbers differ.)

This is a post-peer-review, pre-copyedit version of an article published in History and philosophy of the life sciences. The final authenticated version is available online at: http://dx.doi.org/10.1007/s40656-015-0075-9.

\section{Terms of Use}

Copyright applies. A non-exclusive, non-transferable and

limited right to use is granted. This document is intended

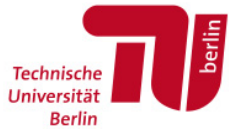
solely for personal, non-commercial use. 


\title{
In Pursuit of a Science of Agriculture: The Role of Statistics in Field Experiments
}

\author{
Giuditta Parolini \\ Postdoctoral fellow, Technische Universität Berlin and Berliner Zentrum für Wissensgeschichte
}

\section{Introduction}

"I do not always agree with Sir Ronald Fisher, but it is due to him that the standard of presentation of results in agriculture is better than in any of the so-called exact sciences; and this is a state of affairs that physicists should cease to tolerate" (Jeffreys 1953: 119). In this way, Harold Jeffreys, geophysicist and statistician, concluded his address to Section A (Physics and Mathematics) of the British Association for the Advancement of Science. Jeffrey's statement shows how, in the mid-twentieth century, the strengths of experimentation in agriculture were widely extolled, and how British mathematicians and physicists, as representatives of the exact sciences, were urged to regard agricultural research as exemplary. Agricultural research was praised for its high standards in estimating uncertainties, standards achieved through the use of statistical methods in the design and analysis of agricultural experiments. ${ }^{1}$ Yet, the application of statistical tools to agricultural research was neither unproblematic nor devoid of consequences for the methodologies of agricultural experimentation. The emergence of statistics, in fact, necessitated a reshaping of both the conceptual tools and the material implements of agricultural research redefining its experimental cultures. ${ }^{2}$ Since the beginning of the twentieth century this transformation became most evident in field trials, one of the main experimental activities undertaken in agriculture.

\footnotetext{
${ }^{1}$ An assessment of statistics as a tool capable of transforming agricultural research into an exact science is already found in Beckett (1929: 268).

2 The definition of experimental cultures suggested here follows Rheinberger (2004).
} 
The paper will discuss the role that statistics came to play in field experiments, and will investigate how statistics took part in the subtle dialectic, proper to experimental systems, between the epistemic and the material (Rheinberger 1997). Rather than conceiving of statistics merely as an instrument to transform agriculture into a quantitative science, I will here explore how changes in the methods and the aims of agricultural research were contingent upon, and influenced by, the actors, the experimental practices, and the forms of institutional organisation that underpinned the statistical approach. The role that statistics had in field experiments in the first half of the twentieth century will be discussed using Rothamsted Experimental Station (RES) as a case study. The statistical methods that are widely used today in the planning and analysis of field experiments were developed at this British agricultural institution in the 1920s. I will argue that statistics at RES promoted randomisation over systematic arrangements, factorisation over one-question trials, and emphasised the importance of the experimental error in assessing field trials. These changes in methodology transformed also the material culture of agricultural science, and a new body, the Field Plots Committee, was created to manage the field research of the agricultural institution.

The statistical methods developed at RES for field experimentation had found an international audience in the first half of the twentieth century, and by the 1950s several manuals and booklets for their application were available to agronomists and statisticians. Yet, the vision of field experimentation as a statistical endeavour centred on randomisation, factorial experiments, and a reliable and accurate determination of the experimental error, was not universally accepted. Even in Britain, experimental scientists closely linked to the farming community questioned the methods of field experimentation proposed by the Rothamsted statisticians in favour of a field research that could be more easily understood by farmers. The clash between the two agendas reveals how the role attributed to statistics in field experimentation defined different pursuits of agricultural research, alternately conceived of as a scientists' science or as a farmers' science. 


\section{Field experiments with plants in twentieth-century agricultural science: an overview}

Field experimentation with both plants and animals is essential in agricultural research (Maat 2011; Maat and Glover 2012). Field trials can be used to tackle a variety of different problems, from finding the best conditions for the growth of cereal crops to determining the mechanism of the transmission of infectious diseases among animals (the latter is examined in Angela Cassidy's contribution to this issue). In the first half of the twentieth century RES was mainly engaged in plant research and conducted field experiments for studying soils and fertilizers. The assessment of different varieties of the same crop with field experiments was instead part of the mission of the National Institute of Agricultural Botany (NIAB) in Cambridge, as described in Dominic Berry's paper in this issue. Pastures, trees and fruit shrubs were also investigated through field trials, but while grassland experiments fell within the remit of agricultural institutions like RES, horticultural research was generally considered a form of specialised knowledge requiring dedicated institutions. An overview of the common types of field trials with plants undertaken in the first half of the twentieth century is provided in Table 1.

Despite the diversity of their aims and features, agricultural and horticultural field experiments had some fundamental elements in common. In all of these field trials the plot was the basic unit and the subdivision of the field in plots was essential to perform comparative and replicated experiments (in replicated experiments the same treatment was applied to more than one plot at a time). Field trials were also repeated in different seasons and geographic areas in order to monitor the interference of environmental factors. Soil and weather, in fact, made field experimentation "a very difficult game indeed", "nearly as difficult [...] as it is to get your ball through the hoop at a game of croquet, when the mallets are flamingos and the balls are hedgehogs". ${ }^{3}$

Beyond the arrangement of the experiment, challenges were also posed by the actual implementation of the trial. The experimental work in the field was carried out under the supervision of

\footnotetext{
${ }^{3}$ These references to Lewis Carroll's Alice in Wonderland can be found in the paper on the principles and practices of yield trials (in relation to variety trials), written by the agronomist Frank Leonard Engledow and the statistician George Udny Yule (Engledow and Yule 1926; quotations p. 112 and p. 146). Yule was employed as a consultant by the Cambridge School of Agriculture.
} 
the scientific staff, but all the major field operations - sowing, manuring, harvesting - ultimately relied on unskilled labour. Since the nineteenth century RES therefore employed a superintendent of the field experiments alongside the farm manager. The superintendent served as a sort of mid-level functionary that mediated between the scientific staff and the farm workers in the implementation of the field trials. To avoid mistakes by illiterate labourers, agricultural institutions often used a colour code to distinguish bags for different manures, sheaves cut at harvest and even to associate the field labourers with the experimental plots on which their work was required (Hoblyn 1931: 46; Moffatt 1939: 258).

Field research, in addition to its scientific merits, offered an immediate connection with farming practices. Even today field trials can be used "to 'make a place for science', controlling the field through experimentation but also trying to maintain the particular, 'authentic' character of a given field" (Henke 2000: 484). The undertaking of field trials was therefore not just the preserve of scientific institutions, like RES, but also of extension services, farming associations, and sometimes even of individual farmers willing to improve their own cultivation methods. For these actors, field experiments acquired different meanings due to the "specific ecological, material and institutional environment" in which the experiments were embedded (Maat 2011: 187). Accordingly, the integration of statistics into agricultural science promoted by RES met with a mixed reception.

Table 1: Popular types of field experiments with plants in agricultural science (ca. 1900-1950)*

\begin{tabular}{|c|c|c|}
\hline Type & Features & Aim \\
\hline $\begin{array}{l}\text { Fertilizer } \\
\text { trials }\end{array}$ & $\begin{array}{l}\text { - The experimental field was divided into } \\
\text { adjoining plots of regular size and shape. Plots } \\
\text { were treated with different fertilizer(s), but, } \\
\text { otherwise, standard cultivation procedures were } \\
\text { applied. } \\
\text { - Fertilizers were allotted to plots randomly or } \\
\text { systematically. } \\
\text { - At harvest the plants growing close to the plot } \\
\text { contours were discarded and the yield of each plot } \\
\text { was recorded separately. } \\
\text { - Control plots were used to evaluate the efficacy } \\
\text { of the treatment against natural conditions. }\end{array}$ & $\begin{array}{l}\text { Fertilizer trials tested the efficacy of a fertilizer or a } \\
\text { combination of fertilizers on the growth of a crop. }\end{array}$ \\
\hline Uniformity & - The experimental field was divided into & Uniformity trials could be used [as stated in \\
\hline
\end{tabular}




\begin{tabular}{|c|c|c|}
\hline Type & Features & Aim \\
\hline trials & $\begin{array}{l}\text { adjoining plots of regular size and shape. The same } \\
\text { variety of crop was grown and the same operations } \\
\text { for manuring and cultivation were carried out on } \\
\text { each plot. } \\
\text { - The yield of each plot was recorded separately at } \\
\text { harvest. Further observations could be collected } \\
\text { during the growth of the crop and used during the } \\
\text { data analysis. In the data analysis adjoining plots } \\
\text { could be amalgamated to form larger plots of } \\
\text { various sizes and shapes and the relative merits of } \\
\text { these arrangements were compared. } \\
\text { - Uniformity trials were performed both in } \\
\text { agriculture (for cereals, root crops and pastures) } \\
\text { and horticulture. }\end{array}$ & $\begin{array}{l}\text { Cochran (1937)]: } \\
\text { - to provide information on the optimal size and } \\
\text { shape of the experimental plots for each crop; } \\
\text { - to compare different types of experimental } \\
\text { designs and to test whether a new proposed design } \\
\text { was suitable for a certain crop; } \\
\text { - to test the heterogeneity of the soil and the yield } \\
\text { correlation between adjoining plots. When they } \\
\text { were set up with this aim, uniformity trials were } \\
\text { preliminary to other types of field experiments; } \\
\text { - to check the applicability of the analysis of } \\
\text { variance to field experiments and to test the quality } \\
\text { of the randomisation process. }\end{array}$ \\
\hline Variety trials & $\begin{array}{l}\text { - The experimental field was divided in adjoining } \\
\text { plots of regular size and shape. Different varieties } \\
\text { of the same crop were grown in the plots with the } \\
\text { same cultivation procedures. } \\
\text { - Varieties were allotted to plots randomly or } \\
\text { systematically. } \\
\text { - At harvest the plants growing close to the plot } \\
\text { contours were discarded and the yield of each plot } \\
\text { was recorded separately. } \\
\text { - Control variety/varieties were chosen among the } \\
\text { crop varieties with the same growth-time of the } \\
\text { plants undergoing testing. }\end{array}$ & $\begin{array}{l}\text { Variety trials tested different varieties of the same } \\
\text { crop for suitability to local conditions, high/low } \\
\text { yield, resistance to specific plant diseases etc. }\end{array}$ \\
\hline $\begin{array}{l}\text { Grassland } \\
\text { experiments }\end{array}$ & $\begin{array}{l}\text { - The experimental area was divided into plots. } \\
\text { The plot size was influenced by the choice of the } \\
\text { grazing animal (sheep, horses or bulls were usually } \\
\text { employed). } \\
\text { - A grazing animal was tethered on the plot and } \\
\text { moved within the experimental area at regular } \\
\text { intervals. The animal required water during periods } \\
\text { of drought and shelter in exposed situations. } \\
\text { - The ecological changes of the plot and the } \\
\text { amount of food provided to the grazing animal } \\
\text { were evaluated through botanical analysis } \\
\text { (counting tiller/plants, etc.). } \\
\text { - Plot replication was possible in experiments with } \\
\text { a tethered animal. } \\
\text { - Control plots were used to evaluate the pastures } \\
\text { tested against the local ones. }\end{array}$ & $\begin{array}{l}\text { Grassland experiments investigated different } \\
\text { intensities of grazing on different types of } \\
\text { grassland in order to assess which were the most } \\
\text { profitable pastures. }\end{array}$ \\
\hline $\begin{array}{l}\text { Horticultural } \\
\text { experiments }\end{array}$ & $\begin{array}{l}\text {-There were two main differences between } \\
\text { horticultural and agricultural experiments. In } \\
\text { horticulture: a) plants were perennials and often } \\
\text { required } 10-15 \text { years before giving experimental } \\
\text { results; and b) there was extreme difficulty in } \\
\text { producing uniform experimental plants starting } \\
\text { from seeds. }\end{array}$ & $\begin{array}{l}\text { Horticultural experiments examined growth, } \\
\text { output quality, and productivity of fruit trees or } \\
\text { shrubs. }\end{array}$ \\
\hline
\end{tabular}




\begin{tabular}{|l|l|l|}
\hline Type & Features & Aim \\
\hline & $\begin{array}{l}\text { Plots could contain a) several dozens small plants } \\
\text { (like strawberries); b) from a few (three to four) to } \\
\text { over twenty bushes (like black-currants); or c) a } \\
\text { single tree (for all the fruit trees). } \\
\text { Experimental designs that required } \\
\text { randomisation might be modified to enable } \\
\text { operations of spraying, picking, pruning, etc. } \\
\text { - Long-term records were produced for individual } \\
\text { trees stating vigour, productivity (blossoms and } \\
\text { weight at harvest), quality of the fruit (through } \\
\text { grading operations), pests/accidents, etc. }\end{array}$ & \\
\hline
\end{tabular}

*The table was compiled using RES (1931) and Cochran (1937). The classification here proposed provides an overview of the field experiments, in the design and analysis whereof statistics became relevant. These types of experiments were not peculiar to British agriculture, but adopted worldwide.

\section{$2 \quad$ Statistics and field experiments at Rothamsted Experimental Station}

RES was set up in the middle of the nineteenth century to study crops and fertilizers (Russell 1966).

The institution, now renamed Rothamsted Research, is still celebrated for its classical experiments, the field trials on crops and fertilizers that have been continued for over 150 years (Johnston 1994). During World War One annual experiments were added to the classical experiments with a considerable increase in the amount of field experimentation done at the agricultural institution (Garner 1962: 180). It is not surprising, therefore, that an interest in the application of statistics to field experiments developed at Rothamsted quite early. Statistical methods, in fact, could offer strategies for improving the planning and analysis of field experiments. During the twentieth century, decisive steps were taken to integrate statistics into the research activity of the agricultural institution (Parolini 2014).

Alfred Daniel Hall (Brassley 2004), the agricultural scientist and civil servant who was in charge of RES from 1902 to 1912, was the first to promote statistics. ${ }^{4}$ In 1909 Hall wrote a contribution on the experimental error in field trials for The Journal of the Board of Agriculture. He was aware that "[f]ield trials, whether they are to test the effects of different manures, or different varieties of the same crop,

\footnotetext{
${ }^{4}$ The creation of the Development Commission (in 1909) and the establishment of the Agricultural Research Council (ARC) twenty years later, promoted the interest of scientifically trained people, like A. D. Hall, for British agricultural science (Brassley 1995). A. D. Hall acted as member of the Development Commission and later of the ARC and was an advisor to the Ministry of Agriculture.
} 
or variations in the cultivation, are generally recognised as being subject to a large number of sources of error". Therefore, Hall used some basic notion of statistics (calculation of averages and probable errors) to explain "what sort of differences in the yields from two plots may be taken to indicate an effect of the treatment they have received, and what must be regarded as covered by the natural variation due to unknown causes" (Hall 1909: 365-366). ${ }^{5}$ A year later Hall and the agronomist W. B. Mercer set up a uniformity trial in the Rothamsted experimental fields to test the problems raised by Hall's paper. From the results of the uniformity trial Hall and Mercer made "an attempt to deduce [...] the most practicable size of plot and the number of repetitions that would reduce the probable error to dimensions less than the differences to be expected in the trials" (A. D. Hall 1931). The results were published in 1911 in the Journal of Agricultural Science (Mercer and Hall 1911).

In their experimental work and later in the data analysis, Hall and Mercer had "to improvise [their] our bricks with a minimum of straw" (A. D. Hall 1931). The mathematical tools adopted were too rudimentary for dealing with the outcomes of agricultural experiments, despite the support they received in their data analysis from the chemist and brewer William Gosset, a pioneer in the application of statistics to agricultural science (Pearson 1939). Moreover, the implements for the fieldwork were at best artisanal and inventive. For instance, "Mercer constructed a thresher for his little bundles of wheat out of an old bicycle frame, on which he used to mount and pedal away in order to knock out the grain, thus combining research and exercise" (A. D. Hall 1931).

In 1912 Hall left RES. Statistics was to be resumed at the agricultural institution only after World War One, when the station, under the management of the agricultural chemist Edward John Russell (Pirie 2004), hired its first statistician, the mathematician and geneticist Ronald Aylmer Fisher (Fisher Box 1978). Fisher's influence on agricultural statistics was profound (Street 1990). In particular, the statistical methods that Fisher developed at RES, analysis of variance and experimental design,

\footnotetext{
${ }^{5}$ When experimental errors are distributed according to the normal curve (Gaussian), a range within one probable error on either side of the mean will include fifty per cent of the data. The probable error is 0.6745 times the standard deviation, mentioned later in the paper.
} 
transformed field experimentation. He introduced randomised trials and factorial designs, and emphasised the relevance of reliable experimental errors. Fisher's work at RES in the 1920s and 1930s, inaugurated the modern techniques of field experimentation. His book, Statistical Methods for Research Workers (1925), was widely cited in agriculture (and biology) as the first publication on statistical experimentation, and a decade later The Design of Experiments (1935) contributed further to disseminate Fisher's ideas on experimental design.

However, it would be reductive to restrict the RES contributions to agricultural statistics only to the work done by Ronald Fisher. When the statistician left RES in the 1930s, the department he had created remained a reference point for agricultural research in Britain and the British Empire. The new head, Frank Yates, a former assistant to Fisher, spent his entire career at RES, applying statistics and computing to agriculture and biology, and in 1948 he became a fellow of the Royal Society as recognition for these contributions. ${ }^{6}$ Besides Yates, other statisticians received training at RES that helped them to forge their careers in agricultural statistics. For instance, John Wishart, another assistant to Fisher, progressed from RES to the Cambridge School of Agriculture as a reader in statistics. William Cochran, Yates' co-worker during the 1930s, also contributed to statistics in agricultural science during the first part of his career. From RES he moved to Iowa State College, a land-grant institution closely connected to the farming community. Even David Finney, who worked with both Fisher and Yates during the 1930s, made his career in agricultural statistics. He was lecturer in the design and analysis of scientific experiments at Oxford University, before moving to Scotland. There he coordinated a consulting service for Scottish agricultural researchers, shaped "along the lines of the Rothamsted statistics department's work in England" (MacNeill 1993: 187). After World War Two, in fact, the RES statistics department became a general statistical and computing service for researchers in

\footnotetext{
${ }^{6}$ See F. Yates' certificate of election to the Royal Society (Ref. EC/1948/25). Yates' election was proposed by R. A. Fisher and seconded by the botanist E. J. Maskell, a plant physiologist who had collaborated at RES with Fisher in the development of analysis of variance and experimental design. On Yates' contributions to complex designs for agricultural experiments and tools for statistical analysis, see Finney (1995: 559-560).
} 
agriculture and biology, expanding its activities well beyond the agricultural station where it was located (Parolini 2013: chapter 4).

Yates, Finney, Cochran, and Wishart promoted the dissemination of the field experimental techniques developed at RES with the publication of books, technical communications and papers addressed to both statisticians and experimental scientists. During the 1930s, Frank Yates' publications - for instance, Yates (1937 and 1939) - mainly focused on the analysis of agricultural experiments and the design of new arrangements suitable for field trials. Finney's An Introduction to Statistical Science in Agriculture (1953) was based on a series of lectures given by the author to the undergraduates studying agriculture at Oxford University, while Cochran's Experimental Designs (1950), co-authored with Gertrude Cox, owed much to the experience of Cochran and Cox as consultants of agronomists and biologists. Wishart's Field Trials: Their Layout and Statistical Analysis (1940) was a simplified account of the statistical methods of field experimentation. It was published by the Commonwealth Bureau of Plant Breeding and Genetics, an information service for agricultural science in Britain and the British Empire. ${ }^{7}$ The reviewer of Wishart's book for Agricultural Progress, a journal devoted to agricultural education and research, concluded that it was "a very handy booklet to have at one's elbow" even though the pages offered "such a solid block of type that the ordinary non-mathematically minded reader may well be frightened away" (Anonymous 1940). By the mid-1930s dozens of papers and books related to the application of Fisher's statistical methods to field experiments were listed in the bibliography prepared by the Industrial and Agricultural Research Section of the Royal Statistical Society (Wishart 1934). Due to the rapid diffusion of the methods developed at RES, previous contributions on the principles and practices of yield trials for agronomists had also to be fully redesigned. Fisher's books were widely drawn upon in this efforts to keep pace with the changing techniques adopted in field experiments (Wishart and Sanders 1935).

\footnotetext{
${ }^{7}$ Since the 1920s British agricultural science was an enterprise with ambitions for both the homeland and the colonies of the Empire. In 1927 an Imperial Research Conference was held for agricultural scientists. One immediate outcome of the conference was the publication of the Empire Journal of Experimental Agriculture. More information on the imperial ambitions of British agricultural research is provided in Charnley (2013).
} 


\section{$3 \quad$ Field trials as experimental systems in agricultural science}

In scientific research, argues Hans-Jörg Rheinberger (1997), "practices and concepts [...] 'come packaged together"' (p. 28), and experimentation, far from being the theory-driven rationalistic enterprise advanced by many accounts in the philosophy of science, rarely deals with "well-defined empirical instances [...] performed in order to corroborate or to refute certain hypotheses" (p. 27). Instead, a researcher is generally confronted "with a whole experimental arrangement designed to produce knowledge that is not yet at his disposal" (p. 27). ${ }^{8}$ To account for this dynamic, Rheinberger has coined the notion of experimental systems, conceived as "the smallest integral working units of research" (p. 28). Experimental systems have been introduced in relation to laboratory research in biology, but the concept can be applied more widely. Christophe Bonneuil (2006), for instance, has resorted to experimental systems for making sense of the complex relationship between Mendelians and plant breeders in France, but it is agricultural science at large that offers suitable examples.

Field trials are among the most complex experimental systems in agricultural research. They are affected by multiple environmental factors, their performance requires many skills and social actors agronomists, extension services, farmers, field workers, entrepreneurs -, and they rarely allow for an unambiguous interpretation of the data. Above all, they are expected to produce knowledge that contributes at the same time to agricultural science and to the improvement of farming practices. Unlike the experimental systems of laboratory biology examined by Rheinberger, field experiments are in fact evaluated not just as contributions to scientific research, but also for their usefulness to farmers and consumers of agricultural products. Epistemic issues and practical goals are therefore interconnected in their planning and implementation. Since the eighteenth century, debates about the best way to perform field experiments dominated agricultural science. For farming, the importance of field trials centred mainly on the cost-effectiveness of cultivation practices and the maximisation of yields. However, what mattered and what not in field experimentation was still an object of contention

\footnotetext{
${ }^{8}$ A more comprehensive overview of the philosophical contributions useful for understanding agricultural experimentation is provided in the introduction to this special issue.
} 
at the beginning of the twentieth century. By then statistics seemed a promising tool for field experimentation, not only in Britain, but also in continental Europe, Scandinavia and the United States. Yet the statistical methods available were not really suitable for agricultural research (Swijtink 1982: 32), and Fisher has been widely credited for the progress his work represented in this area (Parolini 2013: $53-54)$.

Rheinberger's description of experimental systems is helpful in understanding the role that statistics came to fulfil in field trials. According to Rheinberger experimental systems are constituted by "two different yet inseparable elements": the epistemic things, i.e. the entities or processes under investigation, and the technical objects that articulate the epistemic things into the practicalities of experimentation (Rheinberger 1997: 28-29). Conceived as a technical object, statistics reconceptualised the making of field experiments in relation to the material arrangement of the trial (plot layout, distribution of treatments or varieties, etc.) and the assessment of experimental errors. In so doing, it constrained the research questions that the experimental scientists could ask. From the statistician's perspective the epistemic things, that is, the factors affecting the yield - genetic constitution of varieties, fertilizers, soil conditions, etc. -, gained scientific meaning only through the instantiation of schemes for field experimentation that were informed by statistical reasoning. The scientific soundness of the experiment, determined by planning and analysis, became more important than the 'appearance' of the trial. The appearance was emphasised instead whenever field experiments were used as demonstrations to convince farmers about the effectiveness of a certain fertilizer, crop variety, or agricultural practice.

The cornerstones of experimental design articulated by Ronald Fisher at RES were replication, randomisation, local control (Fisher 1931: 12), the use of factorial experiments and confounding (Fisher 1934: 48-49). ${ }^{9}$ If replication had been an accepted principle of field experimentation for at least a century, it was Fisher's contribution that wedded replication to randomisation (i.e. the chance

\footnotetext{
${ }^{9}$ As mentioned below, confounding refers to the decision, in relevant cases, to sacrifice information on minor interactions by confounding them with soil heterogeneity.
} 
allocation of treatments or varieties to plots) and local control (i.e. the arrangement of the treatments or varieties in blocks), to produce respectively a valid estimate of the experimental error and to offer strategies for reducing such error. When Fisher left RES in 1933, the agricultural institution was also actively pursuing complex experiments planned with a "factorial arrangement of treatments" (Fisher 1934: 48), and was developing methods of data analysis in which less relevant interactions where ignored, i.e. "confounded" with the soil heterogeneity (p. 48). Fisher's principles of experimental design established during the 1920s remained central in field experimentation at RES. Latin squares and randomised blocks (see Fig. 1), the designs for field trials developed by Fisher, were widely applied at the station and in the other research institutions under its influence. The techniques for field experimentation were further developed by the RES statisticians during the 1930s and 1940s, when Fisher's main interest shifted from agricultural science to genetics.

Fig 1.a Latin square

\begin{tabular}{|l|l|l|l|}
\hline D & C & B & A \\
\hline C & D & A & B \\
\hline B & A & D & C \\
\hline A & B & C & D \\
\hline
\end{tabular}

Latin square with four treatments or varieties (A, B, C, D). In a Latin square, treatments or varieties were replicated only once in each row or column, but the choice among the several arrangements that fulfilled this condition was made at random. Latin squares and randomised blocks were developed by Ronald Fisher with the help of the RES experimental scientists. During the 1920 s these arrangements became widely used for the RES annual experiments.

Fig 1.b Randomised blocks

Block 1 Block 3

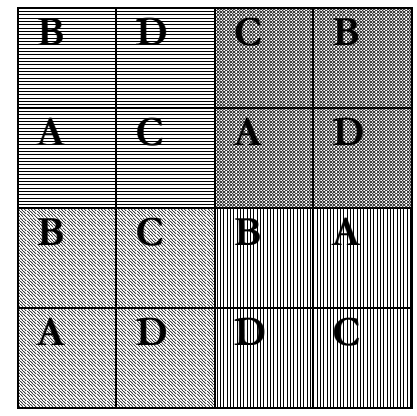

Block 2 Block 4 
Randomised blocks with four treatments or varieties (A, B, C, D). In the scheme there are four $2 \times 2$ blocks. Each treatment or variety appeared once in random arrangement in each block, but, unlike the Latin square, the same treatment or variety could be repeated in the same row or column. Randomised blocks were less accurate than Latin squares, but could be used when the number of replications was not equal to the number of treatments or varieties to be tested

\section{$4 \quad$ Randomisation, factorial experiments and experimental errors}

The practice of randomisation, advocated by Ronald Fisher in the design of field experiments, "is now found in many disciplines, some of them far removed from Fisher's agricultural work" (N. S. Hall 2002: 1), but was contentious among statisticians and experimental scientists engaged in field trials when proposed in the 1920s (Swijtink 1982; N. S. Hall 2007). Before Fisher, agricultural experiments were traditionally set up using replicated designs, in which the treatments or varieties were repeated in more than one plot in each trial. But the distribution of the treatments or varieties to plots followed a systematic pattern, where "care is taken to put the unlike plots as close together as possible, and the like plots consequently as far apart as possible" (Fisher 1926: 506). In Britain two systematic arrangements were most popular: the chessboard arrangement and the half-drill strip method (see Fig. 2). They were mainly used in variety trials. Both arrangements had been proposed by the maltster Edwin S. Beaven (1909 and 1922).

Fig 2.a Chessboard

\begin{tabular}{|l|l|l|l|l|l|l|l|}
\hline A & F & C & H & E & B & G & D \\
\hline B & G & D & A & F & C & H & E \\
\hline C & H & E & B & G & D & A & F \\
\hline D & A & F & C & H & E & B & G \\
\hline E & B & G & D & A & F & C & H \\
\hline
\end{tabular}

Chessboard arrangement with eight varieties (A, B, C, D, E, F, G, H). The chessboard arrangement was used for small-scale variety trials. The experimental area was subdivided in square plots of the same size and was covered with a wire cage to protect the crop. 


\section{Fig 2.b Half-drill strip}

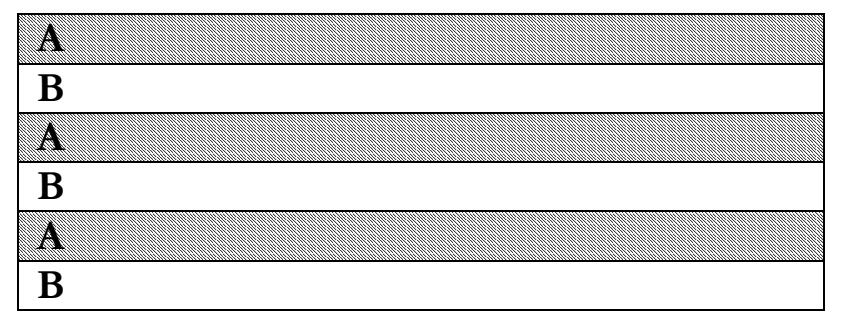

Half-drill strip method with two varieties (A, B). The two varieties were drilled at the same time using a conventional seed drill with the seed box subdivided in two sections and the middle coulter out of action. In this way the two varieties were planted one next to the other and compared in half-drill strips, whence the name of the arrangement. Unlike the chessboard arrangement, the half-drill strip method was used for experiments on a large scale.

In time, Beaven's schemes had been modified to strike a better balance, countervailing possible gradients of fertility in the fields or other systematic biases of the land. The Rothamsted director John Russell, for instance, advised against the systematic design ABABABAB, when comparing two treatments or varieties, and suggested to favour a balanced arrangement ABBAABBA. In the balanced arrangement neither A or B were favoured, while in the systematic design ABABABAB, if soil or drainage conditions worsened on a gradient from left to right, variety or treatment A might be perceived as superior even if, in fact, it was not different from variety or treatment B (Russell 1926; N. S. Hall 2002: 46).

Throughout the first half of the twentieth century, the NIAB in Cambridge, influenced by Beaven, conserved systematic schemes for field experimentation with crop varieties (Berry 2014: chapter 2), not only in its scientific publications, but also in the public presentation of the Institute's activities at agricultural shows. ${ }^{10}$ As discussed by Berry in his contribution to this issue, the NIAB's resources could not support an extensive strategy of randomised trials throughout the country. Moreover, randomised trials did not offer the opportunity for immediate eye-judgements that the NIAB researchers valued in their collaborations with farmers.

Randomisation was resisted even by William Gosset, the chemist and brewer who otherwise supported Fisher's work in agricultural statistics. In his contribution on yield trials for the Baillière's

\footnotetext{
${ }^{10}$ During the 1930 s models of the half-drill strip method for testing cereals were presented for public interest by the NIAB at Royal Shows (Mercer 1931: 143; Watson 1932: 157-158).
} 
Encyclopaedia of Scientific Agriculture, Gosset maintained that the advantages of the systematic schemes were " $[t]$ hat the chances of mistake are lessened by a regular system $[\ldots$ and ...] that the use of such plots for observation purposes is very much facilitated by the ease with which a particular strain may be picked out" (Student 1931: 1345). Gosset also claimed that systematic, but balanced designs, offered more accurate results than the randomised arrangements suggested by Fisher (Student 1938), but to what extent this was convenient remained open to debate in the statistical literature (Yates 1939).

On the other hand, Gosset dismissed - "Be this as it may" (Student 1931: 1345) - the main argument that Fisher and his followers raised in favour of randomised trials, i.e. that only randomisation produced a valid estimate of the experimental error. Gosset acknowledged that the correlation between plots in a field experiment undermined the theoretical principles on which the data analysis was based. However, he was more concerned with the practicalities of field experimentation than with the strict compliance to statistical principles, and did not regard this deviation from sound statistical theory as a serious problem. Nor did he feel the need to account for the possibility that in a systematic experiment the personal biases of the experimenter - for instance, a preference for a certain treatment or variety - could interfere with the making of the trial. Gosset, and in general the advocates of systematic arrangements, relied more on the experimenter's own judgement and personal knowledge of the land than on the "mechanical objectivity" made possible by statistical inference (Daston and Galison 2010): in principle, the decision making process based on statistics required only the mechanical application of rules and thus it was free from any form of personal bias.

Furthermore, the advocates of systematic arrangements were not keenly interested in experimental designs of general applicability as were the statisticians. Latin squares and randomised blocks could be adopted for both small- and large-scale field experiments and used, for instance, in both variety trials and in fertilizer trials. On the other hand, Beaven's chessboard arrangement was only suitable for small-scale experiments, while the half-drill strip, despite permitting experiments with cereal and root crops on large-scale, could not be applied to manurial trials. Also Gosset admitted that with 
the narrow strips introduced by Beaven "there would be danger of the benefit of the manure straying to the neighbouring plot" (Student 1931: 1348).

Even the experimental scientists who accepted randomisation did not fully appreciate the relevance of a valid estimate of the experimental error (Yates 1939: 442). This aspect instead proved crucial when the results of several field experiments had to be compared, as often happened in agricultural research. A valid estimate of the experimental error, in fact, provided "an assurance, not only to the experimenter, but to others who may be more sceptical than he, that the magnitude of the ordinary sources of disturbance, other than those eliminated by the arrangement, has been evaluated by means of the estimate of error" (Yates 1939: 442). In the Rothamsted field trials, which were set up using randomised designs, the experimental error became a yardstick for the reliability of the trial and, as such, it was presented in the reports of the scientific activity at RES. However, while in the 1910s A. D. Hall had framed his data analysis of the field experiments using the probable error, a concept dear to nineteenth-century error theorists, Fisher's methods of error estimation made reference to the newer concept of the standard deviation. The RES reports, widely circulated among agriculturists in Britain and the British Empire, adopted the standard deviation "as the [measure of error] more readily calculated", being the square root of the variance, the quantity on which Ronald Fisher's analysis of variance was based (RES 1927: 122).

Providing a valid estimate of the experimental error with the analysis of variance required considerable computing work and the RES statistics department rapidly became both a statistics and computing centre (Parolini 2014), analysing an increasing number of agricultural experiments year after year. If in 1925 only eight plots were examined by the department, by 1933 the number examined had risen to over 6,500 including not only the experiments done at RES and at the associated station of Woburn, but also in the outside centres that relied on RES for statistical advice and computing work (RES 1934: 31, 42-43). The experimental error of field trials, calculated with the analysis of variance, became a convenient instrument not only to validate the results of the RES field experiments, but also to share the data collected, because simple rules could be used in the interpretation of the experimental 
results. Discrepancies between treatments bigger than three times the standard deviation were suggested as significant, even before undertaking tests of significance, and the conversion between probable and standard error could be easily done with a simple multiplication. Therefore, the results of the RES reports were understandable also for the agronomists more reluctant to keep pace with the developments of statistical theory. ${ }^{11}$

The Rothamsted field experiments during the 1920s changed one more aspect of the practices of agricultural science. While agronomists were often advised to keep field experiments simple, the Rothamsted field trials became factorial experiments, combining multiple research questions into the same trial. Ronald Fisher argued, in fact, that nature would "best respond to a logical and carefully thought out questionnaire", while "if we ask her a single question, she will often refuse to answer until some other topic has been discussed" (Fisher 1926: 511). In his advocacy of complex experiments, Ronald Fisher was at odds with the RES director, John Russell, who claimed that the chief requirement of each agricultural experiment was simplicity (Russell 1926: 989).

In factorial experiments several treatments (the factors) were tested at the same time in different combinations (see Fig. 3). In this way it was possible to gather information not only on the individual treatments, but also on their mutual interactions. Factorial experiments joined economy and accuracy in agricultural science. Though the number of experimental plots required by these trials was large, it was not so many as would have been required to make separate experiments at the same level of accuracy, and the savings made in terms of time, labour and land use were thus evident. As Frank Yates pointed out, however, complex experiments required a better arrangement of the field operations to avoid mistakes. "The preparation of clear and simple plans, and a convenient system of numbering the fertilizer mixtures, etc., that are to be applied, will lighten the work of the man in the field, who is usually operating under averse conditions, is frequently in a hurry, and is sometimes not very certain of

\footnotetext{
11 The presentation of the experimental results became more difficult with the complex experiments (e.g. the factorial experiments) where combinations of several treatments were examined, but even in that case the RES reports gave some 'rough rules' to guide the readers (RES 1934: 98-99).
} 
the points at issue" (Yates 1937: 7). The statistician's remark clearly calls attention to the strong interdependence between the materiality of field experimentation and the knowledge it aimed to obtain. Factorial experiments did not simply entail a reformulation of the research questions asked in field trials, but challenged the institutions interested in performing them to develop suitable arrangements for more complex field operations. Similar considerations apply to the other statistical aspects of field experimentation discussed in this paper. The material and the epistemic, as argued by Rheinberger, are interconnected in experimental systems and technical requirements, in this case the constraints imposed by statistics, "determine the realm of possible representations of an epistemic thing" (Rheinberger 1997: 29).

\section{Fig 3 Factorial experiment}

\begin{tabular}{llll|llll}
\multicolumn{3}{l}{ Block 1 } & & \multicolumn{5}{c}{ Block 2 } \\
$n k$ & $k d$ & $d$ & $n d$ & $k d$ & $d$ & $k$ & $n k$ \\
--- & $k$ & $n$ & $n k d$ & $n$ & $n k d$ & $n d$ & --- \\
& & & & & & & \\
\hline$d$ & --- & $n d$ & $k d$ & $n d$ & $n k$ & $n$ & $d$ \\
$n k$ & $k$ & $n$ & $n k d$ & $k$ & --- & $n k d$ & $k d$
\end{tabular}

Block 3

Block 4

Factorial experiment on the manuring of potatoes (Yates 1937: 9). In the experiment three factors (sulphate of ammonia (n), sulphate of potash $(k)$, dung $(d)$ ) were tested, each considered at two levels ( $n$ : none/0.45 cwt N per acre; $k:$ none/1.12 cwt $\mathrm{K}_{2} \mathrm{O}$ per acre; $d$ : none/8 tons per acre). The experiment was arranged in randomised blocks. The symbol --- is used for the plots on which no fertilizer was applied.

\section{$5 \quad$ Field experimentation, institutional arrangements and labour organisation}

The new techniques of experimentation aided by statistics required more complex arrangements for the setting up of the field trials, and in 1924 a Field Plots Committee was instituted at Rothamsted to manage the field experiments. Throughout its history - lasting to the late 1970s - the Field Plots 
Committee (and the subcommittees and working parties that supported its activity) planned and managed the work in the RES experimental fields providing a forum in which experimental scientists, statisticians and the farm staff in charge of the implementation of the trials could meet and debate the fieldwork (Parolini 2014). Statistical methods and statisticians heavily influenced the action of the Committee. Since the 1920s the principles of experimental design formulated by Ronald Fisher were significantly promoted in the station field trials and, through the Committee, the statisticians had their say on the field operations. Such wide-ranging influence of the statistical consultants was not uncontroversial in the agricultural institution, as shown in the case of the wheat experiment in the Broadbalk field for the season $1933 .^{12}$

Upon the suggestion of the statistician Frank Yates, the Field Plots Committee decided that "headlands should be cut out between each fallow strip of Broadbalk before harvest". ${ }^{13}$ The farm manager Henry Miller disregarded the decision of the Committee on account of the fact that it "would have taken a long time and involved extra expense", and would have prevented the farm staff from taking full advantage of the rapid ripening of the harvest that season. ${ }^{14} \mathrm{~B}$. A. Keen, head of the physics department, firmly reproached the farm manager on behalf of the station director, remarking that, regardless of the peculiarity of the season, "the real issue is that a considered decision of the Director and Plot[s] Committee on one of our classical fields, has been over-ruled by you [Miller] on the grounds of expense and impracticability". ${ }^{15}$ Keen remarked how the insubordinate behaviour of the farm manager was a potential threat to all the fieldwork of the experimental station, "since there would be no guarantee that the details of any experiment were correctly carried out" and to avoid further

\footnotetext{
${ }^{12}$ The correspondence related to this controversy is held in the archives of Rothamsted Research (RR), E. J. Russell Papers, Ref. RUS 2.9. Information on the decisions of the Field Plots Committee is to be found in the minutes of $6^{\text {th }}$ July 1933 and 24 $4^{\text {th }}$ January 1934 (both under the Ref. FX 1.1.2).

${ }^{13}$ Letter from D. J. Watson to B. A. Keen, 28 ${ }^{\text {th }}$ July 1933.

${ }^{14}$ Letter from H. G. Miller to B. A. Keen, 2nd August 1933.

${ }^{15}$ Letter from B. A. Keen to H. G. Miller, 3 $3^{\text {rd }}$ August 1933.
} 
problems for the Broadbalk field, in January 1934 the Field Plots Committee decided that "the headlands [...] should be marked out by paths so as to facilitate the scything" at harvest. ${ }^{16}$

The controversy over the Broadbalk experiment clearly exemplifies how the implementation of field trials remained contentious even in a scientific institution like RES. The farm staff in charge of the day-to-day work on experimental plots did not always realise that the fieldwork had a crucial influence on the statistical analysis of the results, and was as important as the planning of the trial. On the other hand the Rothamsted statisticians were well aware that "a badly planned or carelessly executed experiment will still be inaccurate even though it is randomized" (Yates 1939: 442). To improve the management of the experimental work, the field procedures - from the ploughing of fields to the setting up of the experimental plots; from measuring the weight of the produce at harvest to the recording of results - became more efficiently codified at RES during the 1930s (Moffatt 1939). The same care was required by the field trials performed outside RES. Besides the experiments managed by the Field Plots Committee on the Rothamsted estate, the agricultural institution also promoted fertilizer experiments on the land of commercial farms (Wishart and Hines 1929). Even in these trials Latin squares and randomised blocks were adopted and the Rothamsted staff collaborated with the local farmers in the rigorous implementation of the experiments (Garner 1931: 52).

Field trials on non-experimental farms had some added complications, such as the absence of ad hoc equipment for cultivating small experimental plots, the necessary dependence on local labour to perform the field operations, and the difficulty of using the randomised arrangements for demonstration purposes. Yet, the RES staff insisted on the relevance of these experiments. They presented the opportunity to extend, on different soils and under the ordinary practices of commercial farming, the experimental program of the agricultural institution, and they offered an alternative to the traditional experiments of the demonstration type performed on single or duplicate plots by farmers and advisors working for extension services.

${ }^{16}$ Letter from B. A. Keen to H. G. Miller, 3d August 1933; minutes 24th January 1934. 
While demonstrations had a strong visual impact - the advantage, if any, of a treatment or variety was made self-evident -, they did not provide enough information to compare the outcomes of similar experiments on different lands, nor could they "bring out small differences" (Garner 1931: 49). The results gained with Latin squares and randomised blocks on commercial farms could still be discussed in terms of their standard error and, significantly, in terms of their cash value. The latter was quite a crude measure of their importance, but had an immediate impact for the farmers who had lent their land for the trial (Garner 1931: 53). Experimenting on private land, in fact, meant striking a balance between scientific and practical issues and design experiments with "sufficient practical bearing to appeal to the farmer, while also providing information on more general questions" (Garner 1931: 49). The RES extension services offered to farmers the "modicum of statistical knowledge" required in the interpretation of the results gained with the modern techniques of field experimentation (Wishart and Hines 1929: 531). If Latin squares and randomised blocks could find a place on non-experimental farms, also the knowledge to interpret their results should be at hand. Only then could the pursuit of a statistical approach to field experimentation reach beyond scientific circles and become relevant to the needs of farmers.

\section{Conclusion: Statisticians and research methods in field experimentation}

"The statistician is a good servant but a bad master", argued the maltster Edwin Beaven, criticising the randomised experiments used at Rothamsted. Although Beaven confided in the statistician's advice to turn the comparison of yields of cereals into an exact science performed "with the accuracy obtainable in physical experiments in the laboratory" (Beaven 1922: 344), he maintained that "the justification for agricultural experiments lay in the degree to which they helped the farmer's pocket” (RES 1931: 63). For Beaven agricultural research was an enterprise with practical aims. Experimental concepts, such as randomisation, which made the fieldwork and the general outlook of the experiment hard to grasp for farmers, were a hindrance to this pursuit. As discussed in Berry's contribution to this issue, Beaven, a 
council member of the NIAB, was a key figure in promoting the adoption of the half-drill strip in the Institute's variety trials.

On the other hand, the statisticians that worked at RES or embraced the RES techniques for field experimentation regarded agricultural research as a scientific enterprise. They required that sound statistical principles were strictly adhered to and that the comparison of results gained in different settings was possible through the assessment of the experimental errors. Their contribution to agricultural research was both practical and methodological: they advised on specific designs and performed computing work on behalf of experimental scientists and farmers, but they also established general principles that changed in-depth field trials. In so doing they claimed to fulfil also the practical aims of agricultural experiments offering more accurate advice to farmers (RES 1930: 45-46).

The RES statisticians had a global vision of agricultural research: they aimed to set on the same footing experiments in scientific institutions and commercial farms, investigations of soils and crops in England and in the colonies of the British Empire (Beckett 1929). Their intended public was distributed over a wide geographic area and was socially stratified, involving not only their fellow statisticians or the experimental scientists working in scientific institutions, but also the extension services and the farmers interested in a progressive agriculture. From the 1920s onwards, for this public they wrote dozens of papers, books and pamphlets that aided the dissemination of analysis of variance and of experimental design in field experimentation (and well beyond). Their efforts were certainly rewarded. By the 1930s the techniques of field experimentation developed at RES were adopted, for instance, in the Netherlands and the Dutch colonies by agricultural institutions and extension services (Maat 2008). The RES methods of field experimentation have endured through time. Agronomists are nowadays routinely trained in the use of analysis of variance and experimental design; randomisation is recognised as a necessary requirement in the planning of field experiments; the expert opinion of statistical consultants is sought in designing field trials; statistical evaluation is part of the peer-review process for publication in agricultural research. 
However, the process that brought statistics into field experimentation was not uncontroversial, as argued in this paper, nor did statistical methods transform field trials according to the model of the exact sciences, as many had believed in the first half of the twentieth century. Statistical tools reset both epistemic and material aspects of field experimentation and quantification was just one aspect of this larger process. The questions that the trials were designed to answer, the way in which field operations were performed, even the institutional arrangements for promoting field research had to change to keep pace with the new requirements set by statistics.

The modern methods of field experimentation developed at RES, with their advocacy of randomisation, factorial experiments, and sound experimental errors, were not a refashioning in mathematical language of the old practices of agricultural science. Rather, they established a different experimental culture, centred on the role of statistics as a technical object, and articulated through new material, institutional and social arrangements. In this we find a notable difference from the in vitro systems for the biosynthesis of proteins described by Rheinberger (1997). While in Rheinberger's account the main elements are the choices of the biologists and the material culture of their laboratory, in the case of agricultural research many more social and institutional factors are necessary to understand the development of field experiments.

\section{Acknowledgements}

A preliminary draft of this paper was presented at a panel on experiments in twentieth-century agricultural science at the annual conference of the British Society for the History of Science (2014). I would like to thank the audience at this event for the comments received. Helpful suggestions from two anonymous referees and from Staffan Müller-Wille improved further the manuscript. I am grateful to the Lawes Agricultural Trust for the permission to quote from materials held in the archives of Rothamsted Research. 


\section{References}

Anonymous. (1940). Field Trials: Their Layout and Statistical Analysis by John Wishart [review]. Agricultural Progress, 17(1), 112.

Beaven, E. S. (1909). Pedigree seed corn. Journal of the Royal Agricultural Society of England, 70, 119-139.

Beaven, E. S. (1922). Trials of new varieties of cereals. The Journal of the Ministry of Agriculture, 29(4), 337$347 ; 436-444$.

Beckett, W. H. (1929). Methods of field experimentation. In 1928 Year Book of the Department of Agriculture, Gold Coast, 16 (pp. 266-282).

Berry, D. (2014). Genetics, Statistics, and Regulation at the National Institute of Agricultural Botany, 1919-1969. $\mathrm{PhD}$ dissertation, University of Leeds.

Bonneuil, C. (2006). Mendelism, plant breeding and experimental cultures: agriculture and the development of genetics in France. Journal of the History of Biology, 39, 281-308.

Brassley, P. (1995). Agricultural research in Britain, 1850-1914: failure, success and development. Annals of Science, 52(5), 465-480.

Brassley, P. (2004). Hall, Sir (Alfred) Daniel (1864-1942). Oxford Dictionary of National Biography. Oxford: Oxford University Press, 2004; online edn, May 2014 [http://www.oxforddnb.com/view/article/33647, accessed June 2015].

Charnley, B. (2013). Experiments in empire-building: Mendelian genetics as a national, imperial, and global agricultural enterprise. Studies in History and Philosophy of Science, 44, 292-300.

Cochran, W. G. (1937). A catalogue of uniformity trial data. Supplement to the Journal of the Royal Statistical Society, 40(2), 233-253.

Cochran, W. G., \& Cox, G. M. (1950). Experimental Designs (2nd edition). New York: John Wiley and Sons.

Daston, L., \& Galison, P. (2010) Objectivity. New York: Zone Books.

Engledow, F. L., \& Yule, U. G. (1926). The principles and practice of yield trials. Empire Cotton Growing Review, 3 (2-3), 112-146 (Section I) and 235-267 (Section II). 
Finney, D. J. (1953). An Introduction to Statistical Science in Agriculture. Copenhagen: Ejnar Munksgaard.

Finney, D. J. (1995). Frank Yates, $12^{\text {th }}$ May $1902-17^{\text {th }}$ June 1994. Biographical Memoirs of Fellows of the Royal Society, 41, 555-573.

Fisher, R. A. (1925). Statistical Methods for Research Workers. Edinburgh: Oliver and Boyd.

Fisher, R. A. (1926). The arrangement of field experiments. Journal of the Ministry of Agriculture, 33, 503513.

Fisher, R. A. (1931). Principles of plot experimentation in relation to the statistical interpretation of the results. In Rothamsted Experimental Station, The Technique of Field Experiments (Rothamsted Conferences XIII). Harpenden: Rothamsted Experimental Station; pp. 11-13.

Fisher, R. A. (1934). The contributions of Rothamsted to the development of the science of statistics. In Rothamsted Experimental Station, Report 1933, pp. 43-50. St. Albans: Gibbs and Bamforth.

Fisher, R. A. (1935). The Design of Experiments. Edinburgh: Oliver and Boyd.

Fisher Box, J. (1978). R. A. Fisher: the Life of a Scientist. New York: John Wiley and Sons.

Garner, H. V. (1931). Practical details of experimentation on ordinary commercial farms. In Rothamsted Experimental Station, The Technique of Field Experiments (Rothamsted Conferences XIII). Harpenden: Rothamsted Experimental Station; pp. 49-53.

Garner, H. V. (1962). Field Plots Committee. In: Rothamsted Experimental Station, Report 1961, Harpenden: Rothamsted Experimental Station; pp. 180-183.

Hall, A. D. (1909). The experimental error in field trials. The Journal of the Board of Agriculture, 16, 365370.

Hall, A. D. (1931). Chairman's opening remarks. In Rothamsted Experimental Station, The Technique of Field Experiments (Rothamsted Conferences XIII). Harpenden: Rothamsted Experimental Station; p. 9.

Hall, N. S. (2002). R. A. Fisher and Randomized Experimental Design. Doctoral dissertation, University of Maryland, College Park. 
Hall, N. S. (2007). R. A. Fisher and his advocacy of randomization. Journal of the History of Biology, 40, 295-325.

Henke, C. R. (2000). Making a place for science: the field trial. Social Studies of Science, 30(4), 483-511.

Hoblyn, T. N. (1931). The technique of horticultural experiments. In Rothamsted Experimental Station, The Technique of Field Experiments (Rothamsted Conferences XIII). Harpenden: Rothamsted Experimental Station; pp. 42-49.

Jeffreys, H. (1953). Half a century in geophysics. The Advancement of Science, 10(38), 113-119.

Johnston, A. E. (1994). The Rothamsted classical experiments. In R. A. Leigh, \& A. E. Johnston (Eds.) Long-term Experiments in Agricultural and Ecological Sciences; pp. 9-37. Wallingford: CAB International.

Maat, H. (2008). Statistics and field experiments in agriculture. The emerging discipline of inferential statistics. In J. G. S. J. van Maarseveen, P. M. M. Klep, \& I. H. Stamhuis (Eds.), The Statistical Mind in Modern Society. The Netherlands, 1850-1940. Vol. II: Statistics and Scientific Work (pp. 91-112). Amsterdam: Aksant Academic Publishers.

Maat, H. (2011). The history and future of agricultural experiments. NJAS - Wageningen Journal of the Life Sciences, 57(3-4), 187-195.

Maat, H., \& Glover, D. (2012). Alternative configurations of agronomic experimentation. In J. Sumberg, \& J. Thompson (Eds.), Contested Agronomy (pp. 131-145). New York, London: Routledge.

MacNeill, I. (1993). A conversation with David Finney. Statistical Science, 8(2), 187-201.

Mercer, W. B. (1931). The Agricultural Education exhibit at the Royal Show, Manchester, 1930. Agricultural Progress, 8, 142-144.

Mercer, W. B. \& Hall, A. D. (1911). The experimental error of field trials (with an Appendix by Student). The Journal of Agricultural Science, 4(2), 107-132.

Moffatt, J. R. (1939). Agricultural methods adopted in the Rothamsted classical and modern field experiments. The Empire Journal of Experimental Agriculture, 7(27), 251-260.

Parolini, G. (2013). "Making Sense of Figures": Statistics, Computing and Information Technologies in Agriculture and Biology in Britain, 1920s-1960s. Doctoral dissertation, University of Bologna. 
Parolini, G. (2014). The emergence of modern statistics in agricultural science: analysis of variance, experimental design and the reshaping of research at Rothamsted Experimental Station, 1919-1933. Journal of the History of Biology, DOI: 10.1007/s10739-014-9394-z. Printed in 2015 in Vol. 48(2): 301335.

Pearson, E. S. (1939). Student as statistician. Biometrika, 30(3/4): 210-250.

Pirie, N. W. (2004). Russell, Sir (Edward) John (1872-1965), rev. Oxford Dictionary of National Biography. Oxford: Oxford University Press, 2004; online edn, Jan 2015 [http://www.oxforddnb.com/view/article/35877, accessed June 2015].

Rheinberger, H.-J. (1997). Toward a History of Epistemic Things: Synthesizing Proteins in the Test Tube. Stanford: Stanford University Press.

Rheinberger, H.-J. (2004). Experimental Systems. The Virtual Laboratory (ISSN 1866-4784) http://vlp.mpiwg-berlin.mpg.de/essays/data/enc19.

Rothamsted Experimental Station (1927). Report 1925-26 With the Supplement to the 'Guide to Experimental Plots'. Harpenden: Printed by D. J. Jeffery.

Rothamsted Experimental Station (1930). Report for 1929. Harpenden: Printed by D. J. Jeffery.

Rothamsted Experimental Station (1931). The Technique of Field Experiments (Rothamsted Conferences XIII). Harpenden: Rothamsted Experimental Station.

Rothamsted Experimental Station (1934). Report for 1933. St. Albans: Gibbs and Bamforth.

Russell, E. J. (1926). Field experiments: how they are made and what they are. The Journal of the Ministry of Agriculture, 32, 989-1001.

Russell, E. J. (1966). A History of Agricultural Science in Great Britain, 1620-1954. London: George Allen and Unwin.

Street, D. J. (1990). Fisher's contributions to agricultural statistics. Biometrics, 46(4), 937-945.

Student (alias Gosset, W. S.). (1931). Yield trials. In H. Hunter (Ed.), Baillière's Encyclopaedia of Scientific Agriculture. London: Baillière, Tindall and Cox. 
Student (alias Gosset, W. S.). (1938). Comparison between balanced and random arrangements of field plots. Biometrika, 29(3/4), 363-379.

Swijtink, Z. G. (1982). Randomization in Experimental Design. Doctoral dissertation, Stanford University.

Watson, J. A. S. (1932). The Agricultural Education exhibit at the Royal Show, Warwick, 1931. Agricultural Progress, 9, 156-158.

Wishart, J. (1934). Bibliography of agricultural statistics. Supplement to the Journal of the Royal Statistical Society, 1(1), 94-106.

Wishart, J. (1940). Field Trials: Their Lay-out and Statistical Analysis. Cambridge, School of Agriculture: Commonwealth Bureau of Plant Breeding and Genetics.

Wishart, J., \& Hines, H. J. G. (1929). Fertilizer trials on the ordinary farm. The Journal of the Ministry of Agriculture, 36 (6), 524-532.

Wishart, J., \& Sanders, H. G. (1935). Principles and Practice of Field Experimentation. London: The Empire Cotton Growing Corporation.

Yates, F. (1937). The Design and Analysis of Factorial Experiments (Technical Communication No. 35). Harpenden: Imperial Bureau of Soil Science.

Yates, F. (1939). The comparative advantages of systematic and randomized arrangements in the design of agricultural and biological experiments. Biometrika, 30(3/4), 440-466. 